\title{
Correction to: Effects of AMPK on Apoptosis and Energy Metabolism of Gastric Smooth Muscle Cells in Rats with Diabetic Gastroparesis
}

\author{
Mo-han Zhang ${ }^{1} \cdot$ Xue-sen Fang ${ }^{1} \cdot$ Jun-yu Guo ${ }^{1} \cdot$ Zheng Jin $^{1}$
}

Published online: 4 June 2019

(c) Springer Science+Business Media, LLC, part of Springer Nature 2019

\section{Correction to: Cell Biochemistry and Biophysics}

$$
\text { https://doi.org/10.1007/s12013-019-00870-9 }
$$

Unfortunately, the original version of this article contains a spelling error in word "CaMMK $\beta$ " in the published article. The word "CaMMK $\beta$ " should read as "CaMKK $\beta$ " throughout the article.

The original article can be found online at https://doi.org/10.1007/ s12013-019-00870-9.

1 Department of Histology \& Embryology, Yanbian University College of Medicine, 977 Gong yuan Road, Yanji, Jilin 133002, P. R. China 